\title{
RAMSAY HUNT SYNDROME - A CASE REPORT
}

Geeta Sharma', B. Om Prakash², Dinesh Chandra Govil ${ }^{3}$, S.K. Arora ${ }^{4}$, Ruchika Agarwal ${ }^{5}$

\section{HOW TO CITE THIS ARTICLE:}

Geeta Sharma, B. Om Prakash, Dinesh Chandra Govil, S.K. Arora, Ruchika Agarwal. "Ramsay hunt syndrome - a case report". Journal of Evolution of Medical and Dental Sciences 2013; Vol2, Issue 35, September 2; Page: 6776-6779.

ABSTRACT: Ramsay Hunt Syndrome is a rare complication of herpes zoster in which reactivation of latent varicella zoster virus infection in the geniculate ganglion causes otalgia, auricular vesicles and lower motor neuron facial palsy. A 52-year-old man presented to us with complaints of vesicular eruptions over the right pinna, otalgia and facial weakness i.e. deviation of the angle of mouth to the left side and inability to close the right eye from last 3 days. A diagnosis of Ramsay Hunt Syndrome with grade $\mathrm{V}$ facial palsy was made. Intravenous acyclovir and oral steroids were started. Patient showed marked improvement within 10 days. For facial palsy, rehabilitation therapy was also given.

KEYWORDS: Ramsay Hunt Syndrome, Geniculate ganglion, Facial palsy, Otalgia.

INTRODUCTION: Herpes zoster oticus also known as Ramsay Hunt syndrome (RHS) is a rare complication of herpes zoster in which reactivation of latent varicella zoster virus infection in the geniculate ganglion causes otalgia, auricular vesicles and peripheral facial paralysis. Ramsay Hunt syndrome was first described in 1907 by James Ramsay Hunt in a patient who had otalgia associated with cutaneous and mucosal rashes, which he ascribed to infection of the geniculate ganglion by human herpesvirus 3 (i.e. varicella zoster virus). ${ }^{1}$ Vestibulocochlear nerve involvement may occur in severe cases leading to sensorineural hearing loss in $10 \%$ and vestibular symptoms in $40 \%$ patients. Definitive treatment consists of antiviral therapy and steroids. This article describes the case of RHS with grade $\mathrm{V}$ facial palsy of House-Brackmann grading system ${ }^{2}$ treated effectively with combination therapy of acyclovir and prednisolone, supported by rehabilitation program.

CASE REPORT: A 52-year-old man was admitted with complaints of vesicular eruptions on the right pinna and external auditory meatus, otalgia and facial weakness i.e. deviation of the angle of mouth to the left side and inability to close the right eye from last 3 days. The patient first developed paroxysmal pain deep within the right ear. Within $36 \mathrm{~h}$ after the onset of otalgia, patient developed facial weakness along with vesicular eruptions on the pinna and external auditory meatus of right side. Patient also complains of unclear hearing of right ear, vertigo and tinnitus.

On examination, there were painful adherent crusts and scabs on the right pinna and external auditory meatus and lower motor neuron facial palsy on the right side (as shown in the figure 1, 2 and 3). House Brackmann scoring system was used to grade the severity of facial nerve paralysis. Facial nerve paralysis was found to be of Grade V (Severe). Bell's phenomenon was present on the right side. The oral cavity and oropharynx were normal. Ocular examination was within normal limits.

Enzyme-linked immunosorbent assay test for HIV antibodies was conducted and it was nonreactive. Other routine examinations were within normal limit.

A diagnosis of Ramsay Hunt Syndrome with grade $V$ facial palsy was made. Intravenous acyclovir $10 \mathrm{mg} / \mathrm{kg}$ body weight $8 \mathrm{hrly}$ and oral prednisolone $40 \mathrm{mg}$ daily were started. ENT 
consultant's opinion was also taken. After 5 days, IV acyclovir was stopped and oral acyclovir was given for 5 days more. Patient showed marked improvement within 10 days and then he was discharged on steroids in a tapering dose. For facial palsy, rehabilitation therapy was also started.

DISCUSSION: Ramsay Hunt syndrome is the second most common cause of atraumatic peripheral facial paralysis. Before 1986, the frequency of zoster in patients with peripheral facial paralysis was estimated to be $4.5 \%-8.9 \% .^{3}$ However, a retrospective review of 1507 consecutive Kaiser insured patients presenting with unilateral facial palsy identified Ramsay Hunt syndrome in 185 (12\% patients) based on the triad of facial paralysis, ear pain, and herpetic eruptions in any cranial dermatome. ${ }^{4}$ Ramsay Hunt syndrome is estimated to account for $16 \%$ of all causes of unilateral facial palsies in children, and $18 \%$ of facial palsies in adults. Ramsay Hunt syndrome is rare in children younger than 6 years. ${ }^{5}$

Chickenpox infection during childhood results in an immune response, which leads to VZVspecific cell-mediated immunity. Resolution of the primary infection results in the induction of memory T cells specific for VZV, but the frequency of these T cells and consequent cellular immunity declines over time. The decline below the zoster threshold correlates with an increased risk of herpes zoster.6,7 So, Herpes zoster is seen as a disease of older people (most commonly over 60 years old), and incidence and severity increases with age which may be due to a decline in cellular rather than humoral immunity. ${ }^{8}$ The VZV reactivation in the geniculate ganglia and subsequent neural inflammation, pressure, and possible destruction of the facial nerve in the temporal bone are suspected to cause facial palsy, ${ }^{9}$ while VZV migrates from the geniculate ganglia into the skin around the ear or into the oropharynx via the sensory fibers, where it replicates and produces zoster in RHS. ${ }^{9}$ Frequently, there is involvement of VIII cranial nerve producing hearing impairment and vertigo. Involvement of cranial nerves $\mathrm{V}, \mathrm{IX}, \mathrm{X}, \mathrm{XI}$, and XII occurs less frequently.

The most recommended therapy for RHS is the combination of acyclovir and prednisone. ${ }^{10}$ The largest retrospective Ramsay Hunt syndrome treatment study ${ }^{10}$ showed a statistically significant improvement in patients treated with prednisone and acyclovir within 3 days of onset. The rehabilitation program for facial palsy includes electrical stimulation, infrared radiation, and facial neuromuscular exercises including auto massage, relaxation exercises, inhibition of synkinesis, co-ordination exercises, or emotional expression exercises.

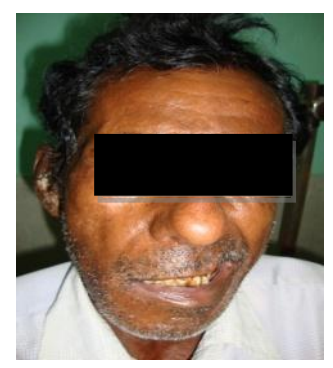

Figure 1.Showing right lower motor neuron facial palsy (inability to close the right eye and deviation of the angle of the mouth towards left side) 


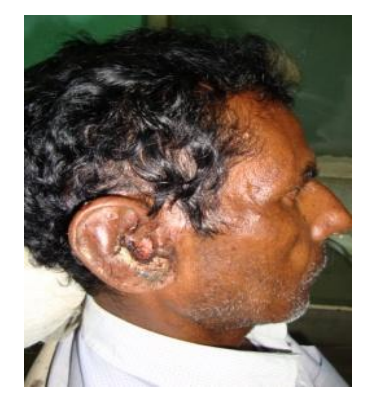

Figure 2. Crust and scab on the right pinna and external auditory meatus formed after rupture of the vesicles.

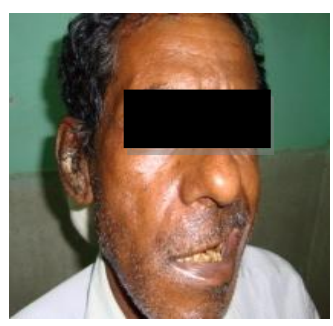

Figure 3. Showing both right sided facial palsy (LMN type) and crust on the right pinna and external auditory meatus.

CONCLUSION: The case has been reported due to its rarity and to demonstrate the usefulness of a combination of steroid and acyclovir therapy in the management of Ramsay Hunt syndrome.

\section{REFERENCES:}

1. Goldani LZ, da Silva LF, Dora JM; Ramsay Hunt syndrome in patients infected with human immunodeficiency virus. Clin Exp Dermatol. 2009 Dec; 34(8):e552-4.

2. House JW, Brackmann DE. "Facial nerve grading system". Otolaryngol Head Neck Surg. 1985; 93: 146-147.PMID3921901.

3. Devriese PP, Moesker WH. The natural history of facial paralysis in herpes zoster. Clin Otolaryngol.1988; 13:289-298.

4. Robillard RB, Hilsinger RL, Jr, Adour KK. Ramsay Hunt facial paralysis: clinical analyses of 185 patients. Otolaryngol Head Neck Surg.1986; 95:292-297.

5. Sandoval C C, Nunez F A, Lizama C M, Margarit S C, Abarca V K, Escobar H R. [Ramsay Hunt syndrome in children: four cases and review]. Rev Chilena Infectol. Dec 2008; 25(6):458-64.

6. Robert W Johnson.Herpes Zoster and Postherpetic Neuralgia. Expert Re Vaccines. 2010; 9(3s): 21-26.

7. Arvin A. Aging, immunity and the varicella-zoster virus. N. Engl. J. Med. 2005; 352:22662267.

8. Burke BL, Steele RW, Beard OW, Wood JS, Cain TD, Marmer DJ. Immune responses to varicella-zoster in the aged. Arch Intern Med. 1982; 142:291-3.

9. Hunt JR. On herpetic inflammation of the geniculate ganglion. A new syndrome and its complications. J Nerv Ment Dis. 1907; 34:73-96. 
10. Murakami S, Hato N, Horiuchi J, Honda N, Gyo K, Yanagihara N. Treatment of Ramsay Hunt syndrome with acyclovir-prednisone: Significance of early diagnosis and treatment. Ann Neurol .1997; 41:353-7.

\section{AUTHORS:}

1. Geeta Sharma

2. B. Om Prakash

3. Dinesh Chandra Govil

4. S.K. Arora

5. Ruchika Agarwal

\section{PARTICULARS OF CONTRIBUTORS:}

1. Assistant Professor, Department of Dermatology, Rama Medical College, Hospital and Research Centre, Mandhana, Kanpur, Uttar Pradesh.

2. Associate Professor, Department of Dermatology, Rama Medical College, Hospital and Research Centre, Mandhana, Kanpur, Uttar Pradesh.

3. Professor and Head of the Department, Department of Dermatology, Rama Medical College, Hospital and Research Centre, Mandhana, Kanpur, Uttar Pradesh.
4. Professor, Department of Dermatology, Rama Medical College, Hospital and Research Centre, Mandhana, Kanpur, Uttar Pradesh.

5. Assistant Professor, Department of Ophthalmology, Rama Medical College, Hospital and Research Centre, Mandhana, Kanpur, Uttar Pradesh.

\section{NAME ADRRESS EMAIL ID OF THE CORRESPONDING AUTHOR:}

Dr. Geeta Sharma, Assistant Professor, Department of Dermatology,

Rama Medical College, Hospital and Research Centre, Mandhana,

Kanpur, Uttar Pradesh - 209217.

Email - docgeetasharma@gmail.com

Date of Submission: 16/08/2013.

Date of Peer Review: 17/08/2013.

Date of Acceptance: 26/08/2013.

Date of Publishing: 30/08/2013 